El tema del amor como juego, sin la grandilocuencia ni la pomposidad de Echegaray, por ejemplo, se relaciona con la concepción estética de Rosita: todo es un juego ligero, sin mayor trascendencia y con características absurdas. El amor es también un intento de escapar a toda influencia realista, se busca la expresión de un ambiente estilizado por medio de recursos plásticos que le restan solemnidad.

Junto al tema del amor se presenta el de la nobleza con derroche descriptivo. Las descripciones se hacen a base de figuras grotescas que critican la realidad de ese mundo que está muy lejos de los ideales que se le atribuyen usualmente. En Rosita temas y técnicas se complementan en una obra artística, cohesiva y con valores propios.

Luis González del Valle

ANTolín González del Valle

Kansas State University.

University of North Carolina at Wilmington.

\title{
LECTURA DE EDUARDO WILDE
}

Yo habria querido petrificar mis sentidos y que la feria continuara eternamente.

"La lluvia"

Llama la atención el aparente desdén con el que Eduardo Wilde habla de la literatura y de sus propios textos. De los prosistas argentinos del ochenta es sin duda el más fragmentario. En vida publica libros de contenido heterogéneo y título nebuloso: Tiempo perdido, Viajes y observaciones, Prometeo y Compañia, Por mares y tierras. Sus obras completas, recogidas póstumamente, ofrecen igual variedad y vaguedad: Recuerdos, recuerdos..., Entre la niebla, Páginas muertas, Aguas abajo. Un crítico se pregunta si practica "un género definitivo o solamente de transición"1. Aguas abajo -cuyo primer capítulo se titula "En la niebla"- oscila entre la autobiografía y la ficción; Prometeo y Compañia reúne cuentos lacrimógenos ("Tini"), artículos costumbristas levemente acidulados ("Vida moderna") y ensueños - término wildeano- como "La Iluvia". La nebulosidad de Wilde se refleja en sus lectores. Mansilla y Cané son también escritores fragmentarios pero no se olvidan La excursión a los indios ranqueles ni la olvidable Juvenilia. En cambio de Wilde se recordarán "páginas escogidas" y "trozos selectos",

1 Nicomedes Antelo, "Estética", en Eduardo Wilde, Tiempo perdido, Buenos Aires, 1923, p. 111.-Abreviaré: Tiempo. 
selecciones mochas porque se destinan "principalmente, a los estudiantes, y a los estudiantes no todas pueden ofrecerse":.

Cuando habla de su tarca literaria comparte Wilde con sus contemporáneos -sobre todo con Mansilla- cierta coquetería torpe. Ambos creen halagar al lector tratándolo con desenfado: "Finalmente, si a usted no le importan las noticias de Tupiza, no las lea y ihabremos concluido! ¿Usted se piensa que yo escribo para usted?"s Sólo puede permitirse tal torpeza quien sabe que sí cuenta con un público a quien le importa Tupiza o, más bien, a quien le importa Eduardo Wilde. La misma seguridad explica las familiaridades de Mansilla ${ }^{4}$ y el inocuo cinismo de Cambaceres en el prólogo de Pot-Pourri. Escribe Wilde de la publicación de Páginas muertas:

Creo que el amor propio tra influido en mi decisión, pero no de un modo fundamental.

Mi motivo preponderante es muy ridículo, no lo defiendo, lo expongo simplemente en honor a la exactitud: tengo una verdadera manía por la simplificación y el orden; me fastidian los papeles sueltos; no podía ver los míos viajando de un lado a otro en manojos desiguales, y como por una razón o por otra, deseo conservar su contenido, he resuelto el conflicto alojando mis producciones en varios volúmenes bien involucrados, previas las enmiendas indispensables, aun cuando sea para leerlas yo solo, imitando a muchos autores impopulares, entre cuyo número me cuento ${ }^{5}$.

Chacoteamos con el lector sobre lo literario porque -después de todo- somos escritores por añadidura. Hay un libro sobre Eduardo Wilde que apenas menciona su actividad literaria: en cambio insiste en su carrera política y diplomática, acumula piadosas noticias necrológicas y enumera las condecoraciones que recibió. También Borges recuerda algunos de estos "honores improbables" para situar a Wilde:

Insisto adrede sobre esas aparentes farolerías para evidenciar qué clase de hombre fue Eduardo Wilde. Hay escritores soslayados y chúcaros (Swinburne, Evaristo Carriego, Rafael Cansinos-Assens) cuya total aventura humana es la de su obra; hay otros de vida cargada, cuya escritura es apenas un rato largo, un episodio de sus pobladisimos dias 6.

Lo mismo puede decirse, sin duda, de todos los escritores del ochenta, salvo quizás de Julián Martel, periodista, escritor-escribiente de profesión.

Parecería haber en Wilde, sin embargo, una actitud algo más compleja. Más allá de la complicidad torpe -digo que no me lean porque quiero que me lean- un desconcierto ante la literatura que se expresa

2 Cf. la introducción de J. M. Monner Sans, a Eduardo Wilde, Páginas escogidas, Buenos Aires, 1955, p. xvi.-Abreviaré: Pág. esc.

3 Eduardo Wilde, Aguas abajo, Buenos Aires, 1964, p. 57.-Abreviaré: Aguas.

4 "Sí, señores y señoras: tengan ustedes un poco de paciencia, lean quand même; y déjenme continuar, según mi método". Entre-nos. Causeries del jueves, Buenos Aires, 1963, p. 140.

5 Eduardo Wilde, Piginas muertas, Minerva, Buenos Aires, s. f., p. 9-Abreviaré: Paig. mue.

6 Jorg. Luis Borges, estudio-epílogo a Páginas muertas, ed. cit., p. 236. 
de manera singularmente desencantada. Recuerda por ejemplo el momento en que rescata los textos de Páginas muertas:

Al remover los papeles hallé las hojas pegadas formando paquetes apelmazados; parecian restos cadavéricos amontonados en una losa común y yo mismo me hice el efecto de estar practicando una exhumación.

¡Páginas muertas!, dije, como leyendo un epitafio imaginario.

¡Muertas!, sí. Unas tuvieron vida efímera ante el público en los perió dicos; otras vivieron sólo en mi conciencia mientras las pensaba y escribía, vaciando la impresión de cada día en el papel, blanco entonces, pálido y macilento ahora!

|Muertas! Lo anuncian los efluvios de su osamenta y lo dejan sentir el silencio y el olvido de su espíritu! (p. 6).

Las expresiones que usa Wilde son apenas metafóricas. Para hablar de lo que David Viñas llamaría su diversión de gentleman emplea términos de su profesión y elige los que más claramente lo obsesionan. La muerte, sobre todo la descomposición: pienso en la fascinada minucia del "Informe médico legal relativo a una autopsia" (Tiempo, 249), la morbosidad de "La primera noche de cementerio", la descripción de los cadáveres y la agonía de Vicentita en Aguas abajo ${ }^{\top}$. Más de una vez asocia Wilde la escritura con la muerte, la separación: el texto es "la expresión helada de las letras" que no logra transmitir "la nota real del sentimiento (Pág. mue., 8); las biografías "son falsas porque contienen, no el retrato del biografiado, sino su copia en el cerebro y las pasiones del biógrafo (Pág. esc., 253); "Uno se muere sin llegar a la forma literaria definitiva" (Aguas, 113). Declaraciones no demasiado sorprendentes, quizás; pero no encontramos su equivalente en la obra de sus contemporáneos. La expresión helada de las letras marca para Wilde un final, la fijación de una distancia irremediable entre lo escrito (helado, sólido, muerto) y lo "sentido" (la nota real, lo vivo, lo móvil). La idea del libro no existe para el Boris de Aguas abajo como no parece existir para Wilde:

Por ejemplo, para hacer un libro -según él- sólo se requería poner un número mayor o menor de palabras, todas diferentes, una tras otra; el mérito de la obra estaba en la relación con la cantidad de éstas: para hacer otro libro se necesitaba otra colección. La idea de que los libros contuvieran frases o dijeran algo no se le vino jamás a la mente. Extraña falta de sentido común inexplicable, pues no se conciben tales aberraciones ante las evidencias de cada momento (p. 64).

En cambio insiste Wilde una y otra vez en la naturalidad, sinónimo para él de lo no escrito, de lo móvil. No llama a Ascasubi literato porque sería condenarlo al destino de los "cómicos idiotas, que mostramos

7 Por ejemplo la impresión de Boris al ver los cadáveres envueltos en Tupiza. $\mathrm{Y}$ el curioso pasaje sobre Boris ante la mesa de disecciones: "Boris, que ha sido siempre algo enamorado, solía llevar los ramitos de flores que le daban las niñas del vecindario y para no tenerlos en su ojal, abría uno en el pecho del cadáver estudiado y colocaba en él las flores, que a favor de la humedad de la herida se conservaban admirablemente. Concluida la disección, el ramito, previamente lavado, volvía al ojal del cual había salido" (Aguas, 146). 
siempre por ficción lo peor que tenemos, guardándonos lo bueno, lo espontáneo, lo natural, lo nuestro, para derramarlo sólo en la conversación familiar (Tiempo, 167). "El arte de hablar o de escribir consiste en la naturalidad", dice Boris (Aguas, 114). Con torpeza -pienso en su polémica con Goyena sobre poesía- intuye Wilde la necesidad de anotar una voz: la voz, diría Borges, del "no escrito idioma argen tino [que] sigue diciéndonos"s. El mismo Borges alaba, con empaque socarrón, esa búsqueda de lo natural en Wilde: "Perteneció a esa especie ya casi mítica de los prosistas criollos, hombres de finura y de fuerza, que manifestaron hondo criollismo sin dragonear jamás de paisanos ni de compadres, sin amalevarse ni agaucharse, sin añadirse ni una pampa ni un comité".9.

Entre la expresión helada de las letras y esa voz que quisiera ser, como dice Borges, "el tono de su escritura"10, se sitúan los textos de Wilde. Entre los miembros de la generación del ochenta sólo él y Mansilla parecen reconocer ese desajuste entre la naturalidad "entre-nos" que pretenden fijar y las posibilidades ulteriores de la letra escrita. Cambaceres lo menciona en sus prólogos pero lo elude en sus novelas más o menos fieles a modelos prefijados; Cané, a pesar de practicar un género más suelto, consigue dar a sus crónicas y relatos de viaje la misma rigidez que reclama, en De cepa criolla, para su grupo social. $Y$ si bien Wilde y Mansilla reconocen el desajuste, lo resuelven de manera muy distinta. Mansilla pretende plegar la letra fija al eternamente flexible entre-nos mediante su inagotable histrionismo: la "desabrochada e intolerable parlería" que criticaba Groussac ${ }^{11}$ deja de ser discurso directo para transformarse en discurso impostado, en gesto tan teatral como el regalo de la capa colorada al cacique Epumer. Wilde, en cambio, reconoce ese desajuste y se instala en él. Para evitar la letra helada y al mismo tiempo escribir, fantasea - con ingenuidad, con persistencia- un lugar intermedio, una nebulosidad obsesiva. Boris, "vivía soñando":

Las entidades concretas, las escenas, las situaciones constituyen para él una incertidumbre, cuyos factores flotan en una atmósfera brumosa como penumbra en el horizonte a la hora del crepúsculo, sin tomar formas definidas en su conciencia, pues apenas intenta dárselas, la realidad del momento se le escapa y la imagen del presente... in un baleno, fugge del nulla in seno (Aguas, 50).

El presente inasible, la alteridad creada por la incidencia del pasado y del futuro en la imagen directa - "una futuridad que la altera" rloc. cit.)-, el desconcierto ante las percepciones simultáneas, encimadas y dispares aparecen en tres términos significativos: flotar, brumosa, penumbras. Por otra parte Boris sufre de "fugas intelectuales", vive en un "ensueño perenne", consciente de "algo incierto", "en una conti-

S Jorge Luis Borges y José E. Clemente, El lenguaje de Buenos Aires, Buenos Aires, 1968, p. 29.

9 Jorge Luis Borges, estudio-epiloge a Páginas muertas, p. 237.

10 J. L. Borges, y J. E. Clemente, op. cit., p. 29.

11 Paul Groussac, Los que pasaban, Buenos Aires, 1939, p 119. 
nua zozobra, envuelto en una vaguedad sin nombre, sin cuerpo, sin sustancia, sin fórmula, sin signo negativo ni afirmativo, sin accidentes ni detalles, sin contornos ni color, sin uno solo de los atributos de las cosas reales, pero eficiente para causarle una inquietud crónica" (ibid., p. 51). La frase de Avellaneda a Boris - "usted no será nunca feliz porque su alma es vagabunda y no sabe lo que quiere, ni va tras objeto alguno conocido sustancial" (loe. cit.)- sugiere erróneamente que esa inquietud crónica es de filiación romántica. De hecho esa vaguedad, esa obsesión con lo fugitivo o inasible, es mucho más precisa.

La alteridad en la que insiste Wilde - pongamos por caso la que siente Boris en Aguas abajo- es sin duda necesaria para establecer ese lugar nebuloso. Vuelvo a la comparación con Mansilla: éste, en "Si dicto o escribo?" 12 postula deliberadamente un secretario aunque "ustedes no creen que yo tengo secretario". Pero el secretario -que a pesar de los coqueteos de Mansilla, sí sabemos que existió- es parte de un nosotros: “ $\mathrm{O}$ no faltaba otra cosa, que mi secretario, que es $\mathrm{mi}$ alter ego, no me elogiara!" El alter ego queda así reducido a una imagen especular y poco importa, en fin de cuentas, que haya o no existido ese representante de "la flor y nata de los secretarios". En cambio en Wilde - por su misma profesión, por una curiosidad que se adelanta a muchas de las preocupaciones del siglo veinte, por una práctica sincera de la modestia, por la búsqueda desconcertada de un yo unitario y decisivo- la alteridad no se resuelve de manera tan satisfactoria. En lugar de unir reconfortantemente el yo y el otro en un histriónico "nosotros", marca un desajuste poco agradable:

Era muy frecuente en Boris ese fenómeno de duplicación de la personalidad, que se verifica en mayor o menor grado, en todo ser humano; veíase y sentíase a sí mismo, y veía y sentía otro individuo idéntico a él, diferente, accesible en general, pero que tomaba a veces ciertos aires de supremacía incómodos.

Cuando tenía un poco de fiebre el fenómeno era intenso; el duplicado parecía más adicto, más apegado y complaciente, más asiduo en la reproducción de todos los actos del enfermo; si éste se daba vuelta en la cama, el otro hacía lo mismo; si tosía o hablaba, el otro, también hablaba o tosía, como un eco. Era un buen compañero, si bien algo molesto; porque eso de tener un testigo y un reflector de cada acto, pegado al cuerpo y al espíritu propio, es poco agradable (Aguas, 52).

El personaje de Boris aparece con frecuencia planteado en términos dobles, a veces contradictorios. A la doble personalidad se añade la doble vista, la doble percepción, la duplicación del recuerdo:

Esta sensación de una doble personalidad no se refería solamente a la suya propia; él veía también, a veces, dos personas en aquella que le interesara.

Quiso mucho a una niña; ésta se hizo mujer, joven, luego adulta y, por fin, vieja. Pues bien, él seguia queriendo a la niña y conociendo sim. plemente a la vieja, que era naturalmente la misma, pero la niña era otra, la que él amó (loc. cit.).

12 Op. cit., p. 314. 
El texto, sin duda menos matizado, no puede no recordar (o anunciar) pasajes de Proust. La mujer querida por Wilde se desdobla como se desdobla el Swann que conoce el narrador de En busca del tiempo perdido: el Swann de Combray no es el Swann padre de Gilberte que ve en los Campos Elíseos; se transforma en "un nuevo personaje". También en Wilde, como en Proust, la supresión de la percepción única lleva a la supresión de un tiempo único, a una dispersión temporal curiosamente expresada:

Cualquier sujeto medianamente avisado sabe, por experiencia, que una escena actual suele presentarse a la mente del espectador con todos los detalles y accidentes ya conocidos de una situación pasada en que se encontró hace tiempo, y aún de una futura que va a realizarse en el momento próximo siguiente, y en la que se ve de antemano, como un recuerdo, la tercera reproducción del mismo espectáculo, sabiendo seguramente y anticipadamente lo que va a suceder... Que se puede tener, en una palabra, la noción de un hecho sucedido dos veces o de uno que va a repetirse inmediatamente (Aguas, 53).

Hay en Wilde, como en Proust, una serie de condiciones que favorecen -más aún, que provocan- la percepción de lo nebuloso, de lo disperso. Por un lado, la enfermedad y el sueño. En Aguas abajo, cuando el protagonista "tenía un poco de fiebre el fenómeno era intenso". En "La lluvia", durante una enfermedad, "mis percepciones fueron, por lo que recuerdo, confusas y sin ilación. [...] Percibía todo, pero como si fuera yo otra persona siendo ante mi juicio un desterrado de mí mismo. [...] Soñaba cosas increíbles, siendo a mi juicio sueños las realidades y realidades los sueños" (Pág. esc., p. 61). En “Tini”, el chico enfermo percibe "ruidos, luces, olores, todo [...] como si viniera de otro mundo, y su cabeza desvanecida poblaba de fantasías increíbles ese cosmos de sensaciones (ibid., p. 95). Por otro lado están las condiciones externas, signadas por lo fluido: la lluvia, el agua, el mar; lo fluctuante: el viaje; lo rítmico: repiqueteo de la lluvia, ruido de las olas, monotonía de máquinas, "ruidos sin sujeto determinado que los produzca" (Aguas, 110). Recuérdese la importancia que adjudica Wilde a la música en el aprendizaje de Boris:

[...] según él, la música en sí no es triste, ni alegre, ni indiferente; ni expresa ni significa idea, sentimiento o acto alguno, no expresa nunca nada y en eso consiste su belleza, cuando es buena, pues todo lo concreto, definido y bien delineado no es a propósito para traer a la mente nebulosidades, únicas impresiones que deleitan, aún cuando sean penosas (Aguas, 107).

Desde luego, Wilde combina varios de estos elementos en la mayoría de los casos en que se produce el ensueño, la nebulosidad. En "La lluvia", la enfermedad y el sueño culminan en esa lluvia que unifica la serie de imágenes inconexas. En "Sueños y visiones" se añaden al sueño -o mejor, lo provocan- el viaje y el ruido del tren:

Dormir soñando, adormecido a medias por el soplo ruidoso de la mítquina y el fragor de los rieles, sorprendidos en su quietud por el brusco 
atropello de los vagones; dormir vareando las distancias como si uno las recorriera en un desmayo, atado al lomo de un caballo furioso; pasar la noche en ese estado de percepción oscura, no sabiendo quién es uno mis. mo y viendo desfilar los amigos de la patria lejana y los objetos confusos de los países recorridos, juntando tiempos separados y ajustando hecho: sin posible ensambladura (Pág. esc., 137).

En "Mar afuera", el ruido "isócrono, que incita al sueño e impide dormir" provoca la "falange de imágenes":

Las visiones, los recuerdos y las inferencias continúan pasando a compás de las olas bulliciosas; la monotonía del movimiento y de los tonos líquidos, sólo se altera por alguna voz lejana de los pasajeros insomnes o por algún estremecimiento proveniente de cadenas arrastradas o de la salida de la hélice en una inmersión desatinada de la proa que ha metido demasiado las narices en el océano.

[...] No sé si se duerme o se está despierto en las noches de a bordo; la vigilia parece un entresueño, y el sueño, una inconciencia durante la cual se perciben, por fajas y a retazos, los acontecimientos cerebrales, pues en verdad, apenas se cree uno despierto, lo primero que oye es el rumor de sístole y diástole de la máquina (Pág. esc., 124-125).

Igual combinación se da en "De Hong Kong a Yokohama", aumentada por el vaivén y el vértigo:

[...] allá en el horizonte, a lo lejos, nuevos ejércitos de fantasmas y escuadras sombrias, como erguidas cordilleras navegantes y con rumbo hacia el buque... avanzan, se aproximan... llegan... la vista sè oscu rece... los oidos se aturden en un golfo de fragores, oyendo apenas cañoneros lejanos... ¡Felizmente el vértigo ha suprimido el espectáculo!.. (Ptig. esc., 148).

Por un lado corteja Wilde lo vago, la nebulosidad que le permite fantasear la nota real y no la expresión helada de las letras. Por otro, se lee en su obra, con igual insistencia y a pesar de su aparente desdén por la letra fija, la obsesión de solidificar, de inscribir esa misma diso lución que se propone. La nebulosidad se presenta como un lugar ambiguo, a la vez proyecto y fracaso. El que desdeñaba la tarea del literato se muestra literato impenitente:

Obras sencillas en apariencia han necesitado una penosa incubación; así, en literatura, por ejemplo, ciertos párrafos encierran toda la vida intelectual de un hombre porque contienen las ideas constituyentes de su haber de conciencia, bagaje que sólo deposita en las paradas de su largo camino, cuando encuentra la expresión acabada de su pensamiento, la ocasión propicia y el momento oportuno para darles vida en fórmula verbal o escrita, pero eficiente, genuina efigie del concepto interno, clara, nítida, estética en sus formas verdadera en su significado.

Nada de ello es aplicable a las presentes páginas; yo no encuentro aún la imagen filológica del sedimento que han dejado en mi alma la visión de la naturaleza, la audición de sus ruidos, la sensación de sus per fumes, la resonancia de sus voces, la misteriosa significación de sus silen 
cios en la noche tranquila a la luz de la luna, siempre serena (Pág. mue., 221).

Además de la impotencia que dicen estas lineas retengo la palabra sedimento porque parece signar la otra vertiente de la escritura de Wilde. La necesidad de asentar, de solidificar, también recuerda la de Proust y opera de manera semejante, a través de una memoria afectiva, vecina de la ficción y del sueño, que permite realizar el sedimento.

Si no soñara uno mientras duerme y no hiciera fantasías mientras está despierto iqué pronto se olvidaría de todo! La noticia de las personas queridas no basta para mantener su imagen en nuestra mente; es necesario evocarla, verla o soñarla.

Así resulta de la observación siguiente: hace diez años que usted no ha visto a un amigo suyo con quien mantiene correspondencia; ésta lo instruye de los negocios del sujeto, de los asuntos de su familia, de los chismes acreditados y de mil otros hechos referentes a él; le deja ver también la decadencia de sus afecciones en la disminución del texto de sus cartas, y la conformidad con la ausencia de usted en la elección de las expresiones, ya más frías y reglamentarias. Todo ello es para usted noticia pura, incapaz de dar la sensación del amigo, pues cuando piensa en él no lo ve a través de los datos transmitidos en diez años, sino a favor de su recuerdo y exactamente como lo dejó, de la misma edad, con el mismo vestido y la misma fisonomía.

Por eso no son buenas las ausencias largas; uno conserva en la mente la última visión y mientras tanto los años han trabajado, y el amigo que usted dejó joven, amable y feliz, es ahora otro hombre, casi un extraño (Pág. esc., 138).

Las semejanzas con las intermittences du coeur proustianas son evidentes y no son las únicas. 'También para Wilde el recuerdo permite anclar, dar verdadera estatura - verdadera realidad- a los seres y a las cosas. Cuando Wilde pasa en revista sus recuerdos, no ve "los objetos del tamaño que se dibujan en la retina sino del tamaño que son" (Tiempo, 133). Ya señalé la duplicación que opera tanto para un autor como para el otro la memoria afectiva. Para Swann el Vinteuil profesor de piano de su abuela y sus hermanas no puede ser el Vinteuil de la sonata: el primero está ligado a los recuerdos de Combray, el segundo queda ligado a su amor por Odette: son personas distintas. Habla Proust de empalmar a un personaje con la serie de recuerdos que lo fija. Wilde dice pegar:

Muchas personas se han desdoblado en mi imaginación. Ahora las trato como a relaciones recientes, mientras las anteriores que son eśas mismas, sin serlo, han muerto, sin dejar de vivir, y pegadas a mis recuerdos en su forma antigua, continúan rodeadas de esa dulce, poética y tierna melancolía que envuelve a todas las cosas pasadas (Pág. mue., 164).

Sedimento, pegar, aferrarse, condensar, incrustar ${ }^{13}$ : todas palabras que utiliza Wilde para afirmar, para consolidar el recuerdo. Adivina una

13 "Esa invencible tendencia que tiene el hombre a aferrarse a cada uno de los momentos de su vida" (Pág. esc., 164); "en el fondo de mi alma, miro los acon- 
estética de la memoria -y en esto se diferencia radicalmente de sus coetáneos para quienes el recuerdo es sobre todo recuerdo colectivo, memoria de clase ${ }^{14}$ - pero no llega a formularla literariamente. Wilde equipara el recuerdo con el sueño, afirma su capacidad realizadora ${ }^{15}$ pero no va más allá. Detenido, quizás una vęz más, por la expresión helada de las letras, no ve en la escritura -aunque de hecho sus textos lo desmienten- la posibilidad de fijar lo móvil en su movilidad misma, como lo hace el recuerdo, y no en la rigidez de lo muerto.

En Wilde la necesidad de realizar, de incrustar, es paralela a la dispersión. Anverso y reverso de esa misma moneda, juegan continuamente a establecer la tensión de lo simultáneo que se da en Wilde como perpetua nostalgia. No sólo el recuerdo sirve para anclar lo pasajero: cumplen idéntica función la descripción de ciertos objetos, la fidelidad al detalle. La tendencia a materializar se observa en Aguas abajo: "cada persona, cada objeto, cada suceso, cada época, cada entidad tuvo para él un color, un sonido, un gusto, un olor, una forma, una semejanza" (p. 63). Se observa, claramente, en el deleite con que Wilde emprende ciertas descripciones, para nada prestigiosas -en el sentido en que quieren serlo, por ejemplo, la descripción de la garçonnière en Sin rumbo de Cambaceres o la descripción de la casa del doctor Glow en La bolsa de J. Martel- sino morosas de cotidianeidad. Se observa en la forma casi sistemática en que Wilde introduce el detalle nimio para incrustar el recuerdo. El ejemplo más conocido es sin duda el de Aguas abajo:

El más lejano recuerdo que tenía de su propia existencia se refiere a la época en que podía tener a lo más cinco años, y a un episodio cómico y doloroso de su infancia.

La más viva imagen de ese recuerdo es aquella en que se ye a sí mismo llorando junto a una puerta pintada de verde, reventando con sus dedos las ampollas de la pintura mal hecha, y observando, sin dejar de llorar, que debajo de la capa verde había una roja (Aguas, 60).

No es el único: en "Recuerdo al caso" Wilde, sentado junto a una muerta, "asentaba en [su] mente todos los objetos, con aquel lujo de detalles que la mente percibe aún en los momentos del más intenso pesar" (Ṕág. mue., 159). En "Mar afuera" el viajero

...se acuesta $[\ldots]$ con el cuerpo molido, el alma molida y la cabeza en torbellino, a rumiar sus recuerdos, a dejar pasar como visiones las escenas de los últimos momentos, las despedidas, los llantos, los apretones de

tecimientos de mi infancia, esperándome que vuelva; ellos son mi grande y perma* nente bagaje, la inolvidable incrustación de mi carácter, de mis impresiones y de mi personalidad" (ibid., 229); "el sentimiento de la inutilidad final de todo en esta vida se condensó en mi mente y se incrustó para siempre en mi conciencia" (Pág. mue., 223).

14 Cf. Lucio V. Mansilla, Mis memorias, Buenos Aires, 1955, p. 65: "Tengo tam. bién una pretensión, modesta pretensión, que confío será coronada de algún éxito. Consiste en ayudar a que no perezca la tradición nacional".

15 En "Ignacio Pirovano" (Pág. esc., 1964). "¿Qué diferencia hay entre la realidad de un suceso y la viva impresión por una representación ideal? ;Soñar con claridad cs, en el momento en que se sueria, tan cierto como tener la realidad presente!" 
manos mecánicos, los sentimientos sinceros, el panorama de la dársena, el pasaje de los coches que lo trajeron a ella, algún accidente insignificante grabado en la memoria porque le ha dado la gana, tal como la capa de goma del cochero con un ojal roto o la figura de un vendedor de lámparas que se encontró al paso (Pág. esc., 122).

Y en "Sueños y visiones", cuando recuerda la muerte de su hermana:

No la vi muerta; me acuerdo sólo de haber entrado el día antes de la catástrofe en una sala grande, sin muebles, haberme acercado a su cama y, oyendo un estertor, haber pensado: “está durmiendo". Le toqué la frente, con mi mano fría hasta el puño, porque las mangas de mi único saquito eran cortas, todavía las veo; su piel quemaba. No sé qué malestar indefinible experimenté; pero me distraje mirando una virgen cataléptica de yeso que había en una rinconera (Pág. esc., 141).

En los cuatro ejemplos citados el detalle material es en sí insignificante, fuera de proporción con la desazón que se intenta recordar, el "torbellino", el "malestar indefinible". Pareceria operar, en el momento mismo, como posibilidad de fuga: "me distraje" dice Wilde. "Un hombre a quien llevan al cadalso, por ejemplo, cuenta los botones de la sotana del sacerdote que lo auxilia, o se distrae con cualquier ocupación análoga" (Aguas, 50). Para escapar de lo sólido se acude a lo nebuloso, para escapar de lo nebuloso se acude a lo sólido: una vez más, tensión de opuestos simultáneos y equivalentes, pese a la desproporción señalada, ya que los detalles nimios del recuerdo tienen la misma importancia que el sentimiento indefinible al que sirvieron de evasión. El detalle incrusta: "las mangas de mi único saquito" y la virgen cataléptica son parte indisoluble de la muerte de Vicentita.

Hay en Wilde una necesidad absoluta de celebrar lo concreto, la materia. La vaga caminata por lugares indecisos que recoge en "Sin rumbo" (Pág. esc., 99) -caminata periférica que anuncia las de Borges: "caminando, caminando, me fui hasta las orillas de la ciudad, cerca de las quintas"- se detiene en la descripción de un almacén:

El arroz, los garbanzos y los fideos se apiñaban en bolsas o barricas, aburridas de su quietud. Las cajas de sardinas, condecoradas con las imágenes de cualquier exposición, proclamaban, mintiendo, la falta de espinas de los cadáveres marítimos que contenian y miraban hacia el mostrador con sus rótulos de metal amarillo. El queso de Gruyère fósil, con sus ojos vacíos, parecía quejarse de la ausencia de consumidores; la yerba mate se ofrecía verdosa e inútilmente; la azúcar amarilla perdía su gusto a fuerza de esperar; los bizcochos y cigarrillos encerrados en vidrieras acostadas se dejaban pasear por las moscas furtivas que habian escapado a un plumero calvo, sirviente antiguo de la casa, el cual en manos del dueño parecía una disciplina destinada a chicotear los objetos más que privarlos del polvo $y$, por fin, sobresaliendo entre las damajuanas, los barriles, las espuelas, los espejos abollados, el pan, las tazas, las bombillas de lata, los confites matizados y eternos, el papel de estraza, las canastas, el hilo emigrado de alguna mercería, los vasitos cónicos, las pantallas de palma, los rosarios y los racimos de velas de baño, se mostraba un cajón de bacalao abierto con sus manjares de cuaresma crucificados, implorando la piedad pública. 
Al comparar a Wilde con Gómez de la Serna, escribe Borges -el Borges "abanderizador del ultraísmo"- que "los dos quieren lo casero del mundo y son como emperadores de cosas quietas" (Pág. mue., 242) . Ciertas descripciones, ciertas protogreguerias de Wilde, anuncian en efecto los textos de Ramón, como anuncia la enumeración citada más de un "collar de imágenes" ultraísta. Para Wilde el barco, bajo la lluvia, "toma un baño de asiento en el océano y recibe una ducha al mismo tiempo", se ladea y es "un sombrero de brigadier puesto sobre la oreja del mar irritado" (Pág. esc., 67), mientras que "el huracán toca el arpa en los cables tendidos" (ibid., p. 147). El chaleco en la silla es un filósofo "muy reflexivo, con sus mangas amputadas" (Pág. mue., 198). El ojo del farol del patio, "urgido por la economía doméstica y la competencia insostenible de la luz solar, se vio obligado a dcjar de pestañear" (ibid., p. 26). El crespón que cubre el llamador de la puerta, cuando muere Tini, tiene "dos piernas desiguales como las de un ahorcado cojo" (ibid., p. 35). El humor de Wilde no siempre es de este tipo; hay páginas ("La carta de recomendación", "Vida moderna") que todo lector recuerda -y que quizás tendría que olvidar, o por lo menos postergar- donde Wilde hace alarde de un humor familiar, de buen tono, reconfortante y en suma inocuo. Parece más interesante señalar la otra vertiente del humor wildeano, menos tranquilizadora, en la que lo sólido cotidiano aparece movilizado, no estático. El emperador de las cosas quietas -descreído de la literatura que se permite escribir "hago llover cuando quiero" (ibid., p. 187) - es también su animador.

Lectura de Eduardo Wilde: quien la practique de manera sistemática posiblemente llegue a un desconcierto, a una nebulosidad, semejantes a los del autor. "Un hombre sin pizca de imaginación" lo llamó Mansilla ${ }^{16}$ que finalmente imaginó menos que él. Pero lo que sorprende al leer a Wilde es observar las caídas de esa imaginación -o de esa literatura-, ver los desniveles de la escritura wildeana, comprobar en casi todo lo que ha dejado (salvo quizás en Aguas abajo donde la óptica infantil propone una unidad un tanto primaria) una continua oscilación entre estilos: el romanticismo trasnochado y cursi junto a las greguerías en "La lluvia", en engolamiento oratorio en "A Palermo" - "Pide a las ondas que besan tu costa el vapor de sus aguas" (Pág. esc., 204) - , la deliberada economía en la descripción de la iglesia de Remedios (Aguas, 108), el lujo de diminutivos sentimentales en "Tini", el humor fácil y bonachón en más de un texto, la minucia de sus descripciones médicas. Los textos de Wilde, por su factura misma, son el reflejo fiel de la incertidumbre que lo obsesiona; como las manos del pianista pretenden "tomar todas las formas y ocupar todos los sitios" (Tiempo, 148). De hecho señalan una indecisión básica entre la expresión helada de las letras (lo que el lector moderno ve como expresión helada e inoperante, lo que quizás el mismo Wilde reconociera) y una mayor soltura ante lo literario, es decir un ejercicio más serio. Indecisión que mina su obra, como la mina el escepticismo del hombre que

16 Entre-nos, p. 189. 
se jacta de haber escrito, durante su vida, "como cuarenta mil páginas, formato cuarto mayor" (Pág. mue., 106) y a la vez propone, como aforismo, "no debe uno apegarse a lo que no ha de durar" (Aguas, 90). De Wilde permanecen fragmentos de fragmentos: los que enriquecen la lectura de sus involuntarios discípulos, los que proponen sus textos.

Sylvia Molloy

Princeton University. 